\title{
Mentoring of SDMUPR Students in Pediatric Dentistry and Academics
}

\author{
MolinaNegrón Damaris* \\ Professor, Assistant Dean for Academic Affairs, School of Dental Medicine, University of Puerto Rico MSC, USA
}

*Corresponding author: Damaris MolinaNegrón, Professor, Assistant Dean for Academic Affairs, School of Dental Medicine, University of Puerto Rico MSC, San Juan, PR, USA

\begin{abstract}
The American Association for Dental Education (ADEA) is working on several initiatives to foster an interest in academic careers. One of these strategies is a student fellowship aimed at allowing the student at the School of Dental Medicine to explore early experiences in academia. In 2016, the School of Dental Medicine of the University of Puerto Rico (SDMUPR), Medical Sciences Campus, began this fellowship. A pipeline of SDMUPR students with interest in pediatric dentistry and academics has evolved from this initiative.
\end{abstract}

Keywords: The pipeline of future pediatric dentists; mentoring in pediatric dentistry

Abbreviations: ADEA:American Association for Dental Education; SDMUPR: School of Dental Medicine of the University of Puerto Rico

\section{Introduction}

The School of Dental Medicine of the University of Puerto Rico (SDMUPR), Medical Sciences Campus, began in 2016 an ADEA Fellowship Program in Dental Academic Careers (ADEA/ADCFP) to encourage students to discover and experience the options available in the academic work setting[1]. This initiative began a parallel pipeline. Students with interest in academics and pediatric dentistry applied continuously to the ADEA/ADCFP and achieved successful educational projects in pediatric dentistry with their mentor assistance. This article will relate the SDMUPR4 years' experience with this pipeline project of future pediatric dentists with interest in academics.

\section{Discussion}

ADEA's Dental Academic Careers Fellowship Program was founded in 2006 to provide students and residents of the USA and Canadian Dental Schools with the opportunity to venture into academia, providing a structured mentoring to be able to observe and reflect on what an academic career requires[1]. The student is required to complete eight components during the ADEA Fellowship Program in Dental Academic Careers. These components include building an action plan, bi-monthly meetings with a mentor, reflective essays before and after an academic experience, interviews with faculty, academic practice, research practice, presenting a poster, and submitting a portfolio with the evidence of all activities made[1]. In 2016, the SDMUPR began with the ADEA/ADCFP with SDM/UPR students. Since then, every year, at least one student applies to the pediatric dentistry track (Table 1). The mentor is a pediatric dentistry faculty at the SDMUPR, and they work together for eight months on a pediatric educational dentistry track project (Figures 1-3). The number of Applications and First-year Enrollment for Advanced Dental Education Programs continues to rise in the USA[2]. With proper guidance and early experiences, the students can learn and explore their areas of interest in dentistry.

Table 1: SDMUPR ADEA/ADCFP Fellows.

\begin{tabular}{|c|c|c|c|}
\hline $\mathbf{2 0 1 6 - 2 0 1 7}$ & $\mathbf{2 0 1 7 - 2 0 1 8}$ & $\mathbf{2 0 1 8 - 2 0 1 9}$ & $\mathbf{2 0 1 9 - 2 0 2 0}$ \\
\hline Five SDMUPR & Ten SDMUPR & Nine SDMUPR & Six SDMUPR \\
ADEA/ & ADEA/ & ADEA/ & ADEA/ \\
ADCFPstudents. & ADCFPstudents. & ADCFPstudents. & ADCFPstudents. \\
\hline
\end{tabular}




\begin{tabular}{|c|c|c|c|}
\hline One SDMUPR & Two SDMUPR & Two SDMUPR & Two SDMUPR \\
ADEA/ & ADEA/ & ADEA/ & ADEA/ \\
ADCFPstudent & ADCFPstudent & ADCFPstudent & ADCFPstudent \\
on Pediatric & on Pediatric & on Pediatric & on Pediatric \\
Dentistry Track. & Dentistry Track. & Dentistry Track. & Dentistry Track. \\
\hline
\end{tabular}

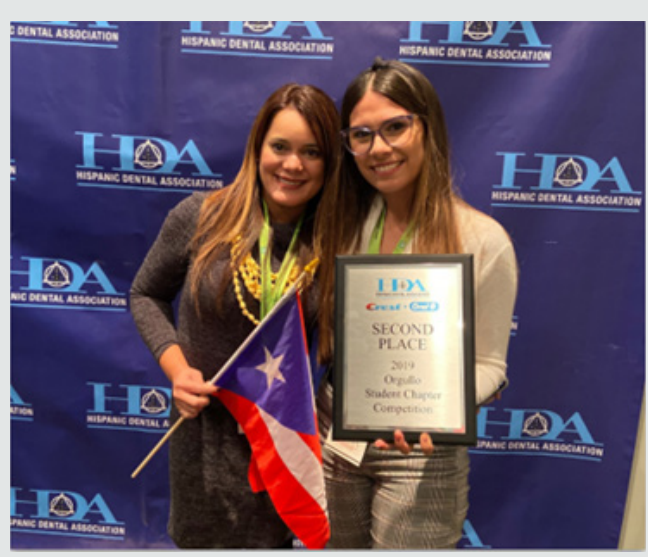

Figure 1: Faculty and student participating in academic activities.

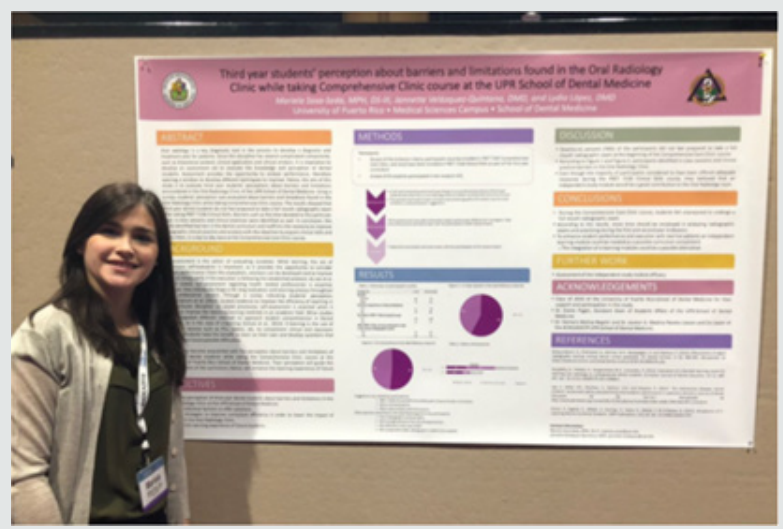

Figure 2: Student presenting a poster at ADEA's Annual Meeting.

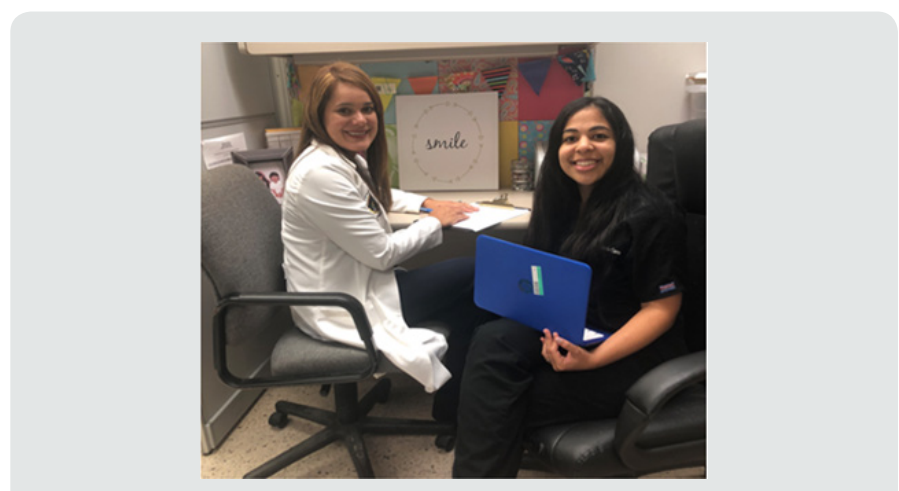

Figure 3: Faculty and student in by-monthly meetings.

\section{Conclusions}

Twenty-six students have completed the ADEA Academic Dental Careers Fellowship Program at the UPRMSC School of Dental Medicine and one of the students who participated in the Program in 2016, currently is a pediatric dentist, from the 2017-2018 cohort, two are pediatric dentistry residents at the SDMUPR, and from the 2019-2020 cohort, one applied to pediatric dentistry programs and is waiting for interviews invitations.

\section{Acknowledgments}

We want to thank Dr. Jocelyn Medina Paneto, professor and co-liaison of the SDMUPR ADEA/ADCFP, Dr. Carla Rodríguez, main mentor of the pediatric dentistry track, and all the faculty of the School of Dental Medicine of the University of Puerto Rico, Medical Sciences Campus, for their collaboration in this Program.

\section{Conflict of Interest}

The author of this article has no conflict of interest to disclose.

\section{References}

1. American Dental Education Association (2020) ADEA Academic Dental Careers Fellowship Program.

2. American Dental Education Association (2020) ADEA Snapshot.

\section{CC) (P) This work is licensed under Creative}

To Submit Your Article Click Here:

Submit Article

DOI: $10.32474 /$ IPDOAJ.2020.04.000196

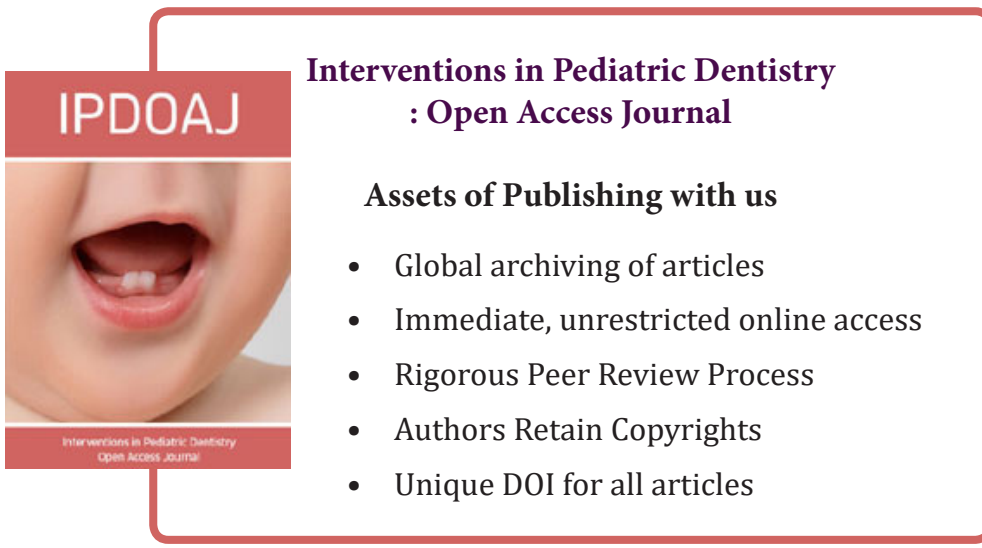

